\title{
What Future for Planetary Science in Britain?
}

WHAT follows is an account of an informal exchange of views at the Royal Society on November 14.

Stimulated by the arrival of the first lunar samples a few weeks ago, people are debating whether the arrangements for planetary science in Britain are satisfactory. Are British scientists doing enough of this work and is it the right kind? Are British scientists adequately informed of the golden opportunities for participation in future Apollo missions and in the exploration of Mars? By multiplying the number of laboratories involved in planetary science, the arrival of the lunar samples has spotlighted problems of coordination between groups which belong to different disciplines and which owe allegiance to different research councils. Some people, notably Dr G. Fielder of the University of London Observatory, are wondering whether there ought to be some kind of planetary science centre in Britain (Nature, 224, 99; 1969).

So far, the British involvement in the Apollo programme has gone well. The chairman of the meeting, Professor S. K. Runcorn (University of Newcastle), said that, according to some NASA officials, the British programme for sample analysis had received more thought than the American. Even so, some people who might have contributed usefully to the analysis did not hear of the opportunity until too late. Professor Runcorn blamed the habit of some professors of not passing on information.

The financial scene was set by $\mathrm{Mr} \mathrm{J}$. Hosie of the SRC Astronomy, Space and Radio Division. Funds for planetary science have to come from the SRC space budget, at present running at $£ 8$ million per year. This figure excludes the financing of the Radio and Space Research Station, the Astrophysics Research Unit and the work on space research at the Royal Observatory, Edinburgh. Out of the $£ 8$ million, the annual contribution to ESRO, which does next to no planetary work, is $£ 5$ million. About $£ 600,000$ is spent on grants to universities, and the rest pays for work on rockets and satellites. But Mr Hosie admitted that the SRC has no coordinated policy in planctary science, and applications are dealt with as they arise. The American offer of lunar samples was taken up by the SRC and the Natural Environment Research Council in a. coordinated effort, and so far the SRC has spent $£ 21,000$ on sample analysis, and Mr Hosie said that no doubt there would be future grants for Apollo 12 and 13 . At the previous meeting of the Space Policy and Grant Committec, $£ 25,000$ was set aside for incidental expenses such as travel to the United States and for preparatory work on the Viking project, the plan to land instrument packages on Mars in 1973.

Mr J. Smith (NERC) admitted that NERC plays second fiddle to the SRC in the space field. NERC supports two postgraduate courses in the planetary sciences, at Newcastle and Exeter, and awards two or three studentships each year in areas relevant to the

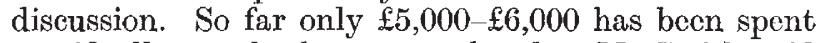
specifically on the lunar samples, but Mr Smith said that the sample analysis is benefiting from an estim. ated $\$ 100,000$ spent during the past four or five years on facilities at the departments concerned. On the question of a national centre, he said that the possibility of setting up a lunar sciences institute in London was discusscd at the most recent meeting of the physical sciences subcommittee of the UGC. Replying to a comment by Dr R. Hide (Meteorological Office) that the role of NERC in the study of planetary atmospheres is unclear, Mr Smith said that this is because the question of NERC support had not yet been raised.

Only a small part of the meeting was devoted to a discussion of profitable research areas for British planctary scientists. A need for a sampling device able to detect elements not distinguished by the alpha scattering experiment designed by Turkevich and his colleagues for the Surveyor series was recognized. Dr Fielder thought a lot could be learned by monitoring the atmosphere of Mars from the Earth, in particular by collating reports of clouds. Dr G. A. Wilkins (Royal Greenwich Observatory) and Dr Hide also stressed that ground-based observations should not be neglected. Professor Runcorn felt that more could be learned from the radio emissions of Jupiter, and this prompted Professor R. C. Jennison (Kent University) to ask what kind of support the SRC gives to radio astronomy at places other than the two centres of excellence. Mr Hosie said that there is access to the facilities at Jodrell Bank and Lords Bridge. He added that an SRC working party under Professor F. G. Smith is considering the need for a comparatively small facility (but nevertheless costing about \&l mil. lion) to operate over the wavelengths $3 \mathrm{~mm}$ to $3 \mathrm{~cm}$.

Although people were given plenty of time to prepare proposals for experiments on the Apollo 11 samples, the same has not been true for later American offers (see Nature, 224, 102; 1969). Professor Runcorn regretted that more notice was not given of the October 20 deadline for the submission of experiments to be carried on the Viking missions. But it may not be too late for last-minute ideas, according to Mr Hosie, who said that if any proposals come forward soon they will be forwarded, although the process of selection is about to start in the United States.

Not much time is expected either for the sub. 
mission of experiments to be carried on the "grand tour" of the outer planets which is being talked about in the United States. Planning for the mission will have to start soon if it is going to take advantage of a favourable arrangement of the planets, and it would do no harm to start thinking about possible experiments. Mr Hosie agreed with Dr Hide that the Americans are not likely to let inexperienced groups take part in projects such as the grand tour in which equipment has to work perfectly after being dormant for years. Professor R. L. F. Boyd (University College, London) said that many space research groups had spare flight models which had been gathering dust for the time it would take to reach the outer planets, and it would be interesting to see if they still work.

Not everyone supported Dr Fielder's call for a planetary science centre. Mr Hosie wondered what was special about planetary science that a centre needed to be set up. According to Professor Boyd, "a central organization will kill any subject", and all that was wanted was good coordination between laboratories. Mr Smith said that it would be impossible to find in one laboratory the expertise of the seven groups working on lunar petrology in the NERC programme.

The first thing a geologist wants to know when he is handed a piece of rock is where it came from, and Dr Fielder thought that many of the geologists at present examining lunar rock would get more out of their experiments if the background knowledge which they needed was explained to them, possibly via a central organization. Really what he was asking for was better communications, but this could best be achieved by bringing groups together. At present British work on the planets is most inefficient. Dr S. O. Agrell, a geologist at Cambridge University, agreed with Dr Fielder. The supply of background information from NASA is inadequate, and he wanted someone to explain to him the meaning of astronomical observa. tions of the Moon. In reply to Mr Hosie, he said the reason that planetary science needs some kind of centre is that not all universities have astronomy departments to supply the background.

Several people at the meeting favoured a number of small centres scattered around Britain. These included Dr G. Eglington, who is examining lunar samples at the chemistry department at the University of Bristol (who said that people like himself are at a disadvantage compared with those who have been doing space physies), and Dr A. J. Meadows of the University of Leicester. The idea is that the centre would house a small number of scientists who would teach service courses in several science departments but that a large number of scientists would play a peripheral part. Dr G. Turner of Sheffield University wondered whether the usefulness of such a centre would be not so much in research as in the postgraduate teaching-geology for physicists and so on. Dr Hide slyly pointed to the example of geology schools in the United States which had found planetary sciences no help in the recruitment of undergraduates.

Several people at the meeting had used the term "institute", and Mr Hosie thought this was the wrong word for what was being talked about. The SRC and NERC do not follow the pattern of the medical and the agricultural research councils in financing institutes; research grants are channelled to established people in the universities.
Dr J. E. Beckman (Queen Mary College, London) raised the problem which a small group has of finding money for complex projects, but Mr Hosie thought that the remedy was cooperation between laboratories. Professor Boyd said his group favoured discussion with anyone who shared their interest and enthusiasm. Mr Hosie added that the technical facilities of ESRO are available to individual member countries, provided they are prepared to pay.

The need for better communication between disciplines seemed to be agreed by everyone at the meeting, and the question was how to achieve it. The interdisciplinary "talking shops" of the kind which the Royal Society has set up on marine pollution and on population might fit the bill, Dr D. C. Martin (Royal Society) suggested to the meeting. Such a group might meet three or four times a year, but it could only be set up if the subject is too broad to be covered by the meetings of a small number of the disciplinary societies. People agreed that this was an idea worth thinking about, and that the great concern which the meeting felt about the future of British planetary science ought to be communicated to the UGC.

\section{Years Ago}

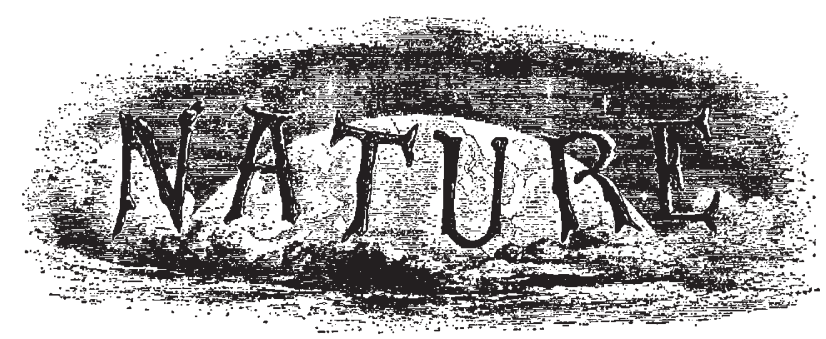

A WEEKLY ILLUSTRATED JOURNAL OF SCIENCE.

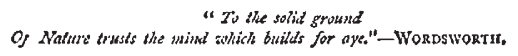

Ethnological Society, Nov. 23.--Prof. Huxley, F.R.S., President, in the chair.-Dr. G. W. Leitner gave an account of his visit in 1866 to Ladak, Little Tibet, Kashmere, and the unvisited country of Ghilghit. He succeeded, by a new route crossing the Shingun and Maraug, in reaching Ladlak six weeks before the usual passes were open. The Abbot of Pugdal-the Buddhist monastery where Csoma de Körös spent five years-agreed with him to secure the safe passage of any English or Hungarian traveller to Lassa; offering to give a near relative of his own as hostage for the safety of the visitor. The Punjab Government having commissioned him to obtain information respecting the Chilasi people, with a view of tracing a connection between them and the Darada, and the Hindı Olympus, the Kaylas, he crossed the frontier and penetrated into Ghilghit, four marches beyond any previous European travellers. Out of fifty, only two of his followers accompanied him to the country of the dreaded Dards. : Dr. Leitner gave an account of the legends of this people, whom he judges to be a remnant of the most ancient Aryan stock, speaking a highly inflexional and perfect, though unwritten language, and preserving ancient mythologics and traditions of their origin. A singular exception to the Dard dialects is found in the Khajuma spoken by the Hunza people-the robbers of Kunjut-and. Nagyr, which is like no other known language. Dr. Leitner has brought a large collection of Thibetan and Dard curiosities, and an intelligent Yarkandi, who as soldier and trader has traversed nearly all Eastern Turkistan : it is to be hoped that he may be given, during his stay in England, opportunities of learning something of our manufactures and commerce, so that he may carry back to Yarkand a good report of English power, and, we will add, of English hospitality and friendship, which will assuredly bear good fruit in the future conduct of the Yarkandis, who are alrcady well disposed to receive and trade with our countrymen.

From Nature, 1, 118, November 25, 1869. 